\title{
Implementasi Kebijakan Kawasan Tanpa Rokok (KTR) pada Mahasiswa di Lingkungan Sekolah Tinggi Ilmu Kesehatan Hang Tuah Pekanbaru
}

\section{No Smoking Area Policy Implementation On Student In Pekanbaru Hang Tuah Institude Of Health}

Reno Renaldi

Program Studi S1 Ilmu Kesehatan Masyarakat STIKes Hang Tuah Pekanbaru

\begin{abstract}
ABSTRAK
Sekolah Tinggi Ilmu Kesehatan (STIKes) Hang Tuah Pekanbaru sebagai tempat pelaksanaan proses belajar mengajar bagi mahasiswa sekaligus tempat kerja bagi karyawannya, yang mana seyogyanya tempat tersebut menjadi tempat Kawasan Tanpa Rokok berdasarkan Undang-undang kesehatan.Oleh karena itu sejak tahun2011STIKes Hang Tuah telah mengeluarkan kebijakan dalam bentuk surat edaran dengan nomor surat No/09/STIKes-HTP/IX/2011/289/mengenai Kawasan Tanpa Rokok di lingkungan STIKes Hang Tuah Pekanbaru.Penelitian ini dilakukan untuk mengetahui Implementasi kebijakan kawasan tanpa rokok (KTR) pada mahasiswa di lingkungan Sekolah Tinggi Ilmu Kesehatan Hang Tuah Pekanbaru Tahun 2013.Metode penelitian dengan desain Cross Sectional dilaksanakan pada bulan juni-juli 2013. Jumlah sampel 350 orang mahasiswa. Prosedur pengambilan sampel dengan cara Proporsional Random Sampling, pengambilan data menggunakan kuesioner dan analisis data dilakukan secara univariat, bivariat dengan uji chi-square, multivariat dengan uji regresi logistic ganda. Hasil penelitian menunjukkan yang tidak mematuhi kebijakan KTR sebanyak 236 orang (67,4\%), variabel yang berhubungan dengan implementasi kebijakan KTR adalah pengetahuan kebijakan KTR (OR:15,594; 95\%CI: 7,530-32,292) dan lingkungan pergaulan (OR:17,118; 95\%CI:9,455-30,992), variabel yang tidak berhubungan dengan implementasi kebijakan KTR adalah pengetahuan bahaya merokok dan pada variabel ini tidak terdapat counfounding. Diharapkan pihak STIKes Hang Tuah Pekanbaru dengan masing-masing prodi yang ada di STIKes Hang Tuah Pekanbaru untuk melakukan tinjauan dan sosisalisasi tentang Kawasan Tanpa Rokok kepada mahasiswa yang masih merokok di lingkungan STIKes Hang Tuah Pekanbaru.
\end{abstract}

Kata kunci : Impelementasi Kebijakan KTR, Pengetahuan, Lingkungan Pergaulan

\section{ABSTRACT}

College of Health Sciences ( STIKes) Hang Tuah Pekanbaru as the implementation of the learning process for students at the same workplace for its employees, which should be a place where the Smoking Area based health legislation . Therefore since 2011 STIKes Hang Tuah has issued a policy in the form of a circular by the number of letters No. / 09 / STIKes - HTP / IX / 2011/289 / on Smoking Area in STIKes environment Hang Tuah Pekanbaru. This study was conducted to determine No Smoking Area Policy Implementation (KTR) On Student In High School Environmental Health Sciences Hang Tuah Pekanbaru in 2013. Metode research with cross sectional design was conducted in June-July 2013. Number of samples 350 students. The sampling procedure by using of Proporsional, data collection using of questionnaires and analysis of data conducted by univariate, bivariate chi-square test and multivariate multiple logistic regression. The results showed that do not comply with policies KTR 236 people (67.4\%), variables related to the implementation of policies KTR are knowledge policies KTR (OR: 15.594, 95\% CI: 7.530 to 32.292) and social environment (OR: 17.118; 95\% CI :9,455-30, 992), a variable that is not related to policy implementation KTR is knowledge on the dangers of smoking and these variables are not counfounding. It is expected that Hang Tuah STIKes Pekanbaru with each study program is in STIKes Hang Tuah Pekanbaru to do reviews and socialization about No Smoking Area to students who still smoke in the environment STIKes HangTuah Pekanbaru.

Keywords : implementation of policies KTR, knowledge, social environment

\section{PENDAHULUAN}

Pada tahun 2009, pemerintah mengeluarkan Undang-Undang Republik Indonesia No. 36 tahun 2009 tentang kesehatan, yang juga membahas tentang rokok dan kebijakan mengenai kawasan tanpa rokok pada pasal 113- 115. Dalam upaya mewujudkan Indonesia sehat, pemerintah mengeluarkan Peraturan Bersama Menteri Kesehatan dan Menteri Dalam
Negeri No.188/Menkes/PB/I/2011 No. 7 Tahun 2011 Tentang Pedoman Kawasan Tanpa Rokok. Kawasan Tanpa Rokok (KTR) adalah ruangan atau area yang dinyatakan dilarang untuk kegiatan merokok atau kegiatan memproduksi, menjual, mengiklankan dan atau mempromosikan produk tembakau. KTR meliputi fasilitas pelayanan kesehatan, tempat proses belajar mengajar, tempat bermain anak, tempat ibadah, 
angkutan umum, tempat kerja, tempat umum dan tempat lainnya yang ditetapkan (Permenkes No.188 Tahun 2011).

Tabel 1

10 Negara dengan Persentase Perokok Terbesar di Dunia Tahun 2008

\begin{tabular}{ccc}
\hline No & Negara & $\begin{array}{c}\text { \% perokok / } \\
\text { penduduk }\end{array}$ \\
\hline 1 & China & $30 \%$ \\
2 & India & $11,2 \%$ \\
$\mathbf{3}$ & Indonesia & $\mathbf{4 , 8 \%}$ \\
4 & Rusia & $4,8 \%$ \\
5 & Amerika serikat & $4,5 \%$ \\
6 & Jepang & $2,8 \%$ \\
7 & Brazil & $1,9 \%$ \\
8 & Bangladesh & $1,8 \%$ \\
9 & Jerman & $1,8 \%$ \\
10 & Turki & $1,7 \%$ \\
\hline
\end{tabular}

Sumber: WHO Report on Global Epidemik, 2008

Dari data di atas Indonesia dinobatkan sebagai Negara dengan konsumsi rokok terbesar nomor tigas etelah China dan India dan di atas Rusia dan Amerika Serikat.Amerika Serikat berhasil mengurangi jumlah perokok di negaranya sedangkan jumlah perokok di Indonesia semakin meningkat (WHO, 2008).

Menurut Riset Kesehatan Dasar(Riskesdas) pada tahun 2010,Usia rata-rata seseorang mulai merokok secara nasional adalah usia17,6 tahun. Namun untuk usia yang paling dini ada yang memulai merokok dariusia 5-9 tahun. Adapun prevalensi merokok berdasarkan usianya,usia perokok mulai merokok,dimulai dari usia 5-9 tahun sebanyak 1,7\%, usia 10-14 tahun sebesar 17,5\%, pada usia 15-19 tahun $43,5 \%$, pada usia 20-24 tahun sebesar $14,6 \%$, Data tersebut menunjukkan betapa memprihatinkannya perilaku merokok pada remaja di Indonesia. Di Provinsi Riau, persentase penduduk yang perokok jenis kelamin Laki-laki dengan prevalensi 66,8\% sedangkan untuk jenis kelamin perempuan dengan prevalensi 3,6\% dengan total Pervalensi 36,6\% (Riskesdas, 2010).

Sekolah Tinggi Ilmu Kesehatan (STIKes) Hang Tuah Pekanbaru sebagai tempat pelaksanaan proses belajar mengajar bagi mahasiswa sekaligus tempat kerja bagi karyawannya, yang mana seyogyanya tempat tersebut menjadi tempat Kawasan Tanpa Rokok berdasarkan Undang-undang kesehatan. Oleh karena itu sejak tahun2011STIKes Hang Tuah telah mengeluarkan kebijakan dalam bentuk surat edaran dengan nomor surat No/09/STIKes- HTP/IX/
2011/289 mengenai Kawasan Tanpa Rokok di lingkungan STIKes Hang Tuah Pekanbaru. Namun sejak tahun 2011 kebijakan tersebut ditetapkan, masih terlihat dan karyawan maupun mahasiswa yang masih merokok dilingkungan STIKes Hang Tuah Pekanbaru karena masih kuranganya sosialisasi dan informasi tentang kebijakan KTR, Pengetahuan bahaya rokok dapat menyebabkan lingkungan sekitar mahasiswa terutama pada perokok pasif yang menjadi dampak berbahaya yang di timbulkan oleh perokok aktif.

Tujuan penelitian ini adalah Untuk mendapatkan informasi terhadap Implementasi Kebijakan Kawasan Tanpa Rokok (KTR) dan faktorfaktor yang berhubungan Pada Pengetahuan tentang kebijakan KTR Pengetahuan tentang bahaya merokok dan Lingkungan pergaulan Mahasiswa di LingkunganSTIKes Hang TuahPekanbarutahun 2013.

\section{METODE}

Jenis penelitian Kuantitatif dengan desain Cross Sectional dilaksanakan pada bulan juni-juli 2013 dengan populasinya adalah seluruh mahasiswa di Lingkungan STIKes Hang Tuah Pekanbaru berjumlah 3150 mahasiswa. Prosedur pengambilan sampel dengan cara Proposional Random Sampling, sehingga didapat 350 sampel Untuk menentukan ukuran sampel pada jenis desain penelitian kuantitatif analitik diperlukan informasi sebagai berikut :Sampling Error (SE) : 5\%, Confidence Limited (CL): 95\%, Proporsi $36,6 \%$.

Maka berdasarkan tabel Besar Sampel untuk Estimasi Proporsi P dengan Presisi mutlak d dan Derajat Kepercayaan 95\% (Lapau, 2010). Jenis data yang dikumpulkan adalah data primer untuk variabel independen yaitu data yang langsung didapatkan dari responden, yang dikumpulkan dengan teknik membagikan kuesioner, dengan cara menanyakan apa yang ada pada variabel independen (Pengetahuan tentang kebijakan KTR Pengetahuan tentang bahaya merokok dan Lingkungan pergaulan) data sekunder untuk variabel dependen( Impelentasi Kebijakan KTR) .kuesioner dibagikan kepada reponden terlebih dahulu dilakukan uji kuesioner. Dan analisis data dilakukan secara univariat, bivariat dengan uji chi-square, multivariat dengan uji regresi logistik ganda.

\section{HASIL}

\section{Analisis Univariat}

Hasil uji univariat terdapat 3 variabel independen (Pengetahuan tentang kebijakan KTR Pengetahuan tentang bahaya merokok dan Lingkungan pergaulan) dam 1 variabel dependen (Implementasi Kebijakan KTR) distribusi responden dengan pengetahuan yang baik tentang kebijakan KTR sebanyak 206 responden $(58,9 \%)$ dan responden dengan pengetahuan yang tidak baik tentang kebijakan 
KTR sebanyak 144 responden (41,1\%).distribusi responden dengan pengetahuan yang baik tentang bahaya merokok sebanyak 275 responden $(78,6 \%)$ dan responden dengan pengetahuan yang tidak baik tentang bahaya merokok sebanyak 75 responden (21.4\%).distribusi responden yang terpengaruh oleh lingkungan pergaulan sebanyak 156 responden $(44,6 \% \%)$ dan responden yang tidak terpengaruh oleh lingkungan pergaulan sebanyak 194 responden $(55,4 \%)$.distribusi responden yang melaksanakan kebijakan KTR sebanyak 114 responden (32.6\%) dan responden yang tidakmelaksanakan kebijakan KTR sebanyak 236 responden (67,4\%).(lihat tabel 2)

\section{Analisis Bivariat}

Hasil uji bivariat terhadapt 3 variabel variabel yang memiliki hubungan yang signifikan terhadap implementasi kebijakan KTR yaitu pengetahuan tentang kebijakan KTR $(p<0,000)$, pengetahuan bahaya merokok $(\mathrm{p}<0,049)$, dan lingkungan pergaulan $($ Pvalue $=0,049)$. Hasil analisa data diperoleh nilai OR $(95 \%$ CI $)=15,594 \quad(7,530-32,292)$ yang berarti mahasiswa dengan pengetahuan tidak baik terhadap kebijakan KTR beresiko 16 kali untuk tidak melaksanakan kebijakan KTR.Hasil analisa data diperoleh nilai OR $(95 \% \mathrm{CI})=0,571(0,338-0,966)$ yang berarti mahasiswa dengan pengetahuan tidak baik bahaya merokok beresiko 0,5 kali untuk tidak melaksanakan kebijakan KTR. Dan Hasil analisa data diperoleh nilai OR $(95 \% \mathrm{CI})=17.118(9.455-30.992)$ yang berarti mahasiswa yang terpengaruh oleh lingkungan pergaulan beresiko 17 kali untuk tidak melaksanakan kebijakan KTR.(lihat tabel 3)

\section{Analisis Multivariat}

Hasil analisis multivariat dapat disimpulkan bahwa variabel yang terdapat hubungan yang signifikan terhadap implementasi kebijakan KTR adalah pengetahuan kebijakan KTR dan Lingkungan pergaulan. Hasil analisis didapatkan bahwa variabel yang paling dominan berhubungan dengan implementasi kebijakan KTR adalah lingkungan pergaulan artinya mahasiswa yang tidak terpengaruh terhadap lingkungan pergaulanlebih terlaksana 26 kali untuk Tidak terlaksananya dengan lingkungan pergaulanyang benar dimana diperoleh nilai $(95 \% \mathrm{CI})$ $=(12,974-53,493) .($ lihat tabel 4$)$.

Tabel 2

Resume Hasil Analisis Univariat

\begin{tabular}{lcc}
\hline \multicolumn{1}{c}{ Variabel\&Kategori } & n & \% \\
\hline Pengetahuan Kebijakan KTR & & \\
Baik (> Mean / 50 \%) & 206 & 58.9 \\
Tidak Baik ( $\leq$ Mean/ 50 \%) & 144 & 41.1 \\
\hline $\begin{array}{l}\text { Pengetahuan Bahaya Merokok } \\
\text { Baik (> Mean/ 50 \%) }\end{array}$ & 275 & 78.6 \\
Tidak Baik ( $\leq$ Mean/ 50 \%) & 75 & 21.4 \\
\hline $\begin{array}{l}\text { Lingkungan Pergaulan } \\
\text { Tidak Terpengaruh (> Mean/ 50 } \\
\text { \%) }\end{array}$ & 194 & 55.4 \\
Terpengaruh ( $\leq$ Mean/ 50 \%) & 156 & 44.6 \\
\hline $\begin{array}{l}\text { Implementasi Kebijakan KTR } \\
\text { Terlaksana (> Mean/ 50 \%) }\end{array}$ & 114 & 32.6 \\
TidakTerlaksana ( $\leq$ Mean/ 50 \%) & 236 & 67.4 \\
\hline
\end{tabular}

Tabel 3

Resume Hasil Analisis Bivariat

\begin{tabular}{|c|c|c|c|c|c|c|c|}
\hline \multirow{3}{*}{ Variabel } & \multicolumn{5}{|c|}{ ImplementasiKebijakan KTR } & \multirow[t]{3}{*}{ PValue } & \multirow[t]{3}{*}{ OR(95\% CI) } \\
\hline & \multicolumn{2}{|c|}{$\begin{array}{c}\text { Tidak } \\
\text { Terlaksana } \\
\end{array}$} & \multicolumn{2}{|c|}{$\begin{array}{c}\text { Terlaksan } \\
\text { a }\end{array}$} & \multirow{2}{*}{$\begin{array}{c}\text { Total } \\
\text { N (\%) }\end{array}$} & & \\
\hline & $\mathbf{N}$ & $\%$ & $\mathbf{N}$ & $\%$ & & & \\
\hline \multicolumn{6}{|c|}{ PengetahuanTentangKebijakan KTR } & & \multirow{3}{*}{$\begin{array}{l}15,594(7,530- \\
32,292)\end{array}$} \\
\hline Tidak Baik & 135 & 93,8 & 9 & 6,2 & $144(100)$ & & \\
\hline Baik & 101 & 49,0 & 105 & 105 & $206(100)$ & 0,000 & \\
\hline \multicolumn{6}{|c|}{ PengetahuanTentangBahayaMerokok } & & \multirow{3}{*}{$\begin{array}{l}0.571(0.338- \\
0.966)\end{array}$} \\
\hline Tidak Baik & 43 & 57,3 & 32 & 42,7 & $75(100)$ & & \\
\hline Baik & 193 & 70,2 & 82 & 29,8 & $275(100)$ & 0,049 & \\
\hline \multicolumn{6}{|c|}{ LingkunganPergaulan } & & \multirow{3}{*}{$\begin{array}{l}17.118(9.455- \\
30.992)\end{array}$} \\
\hline Terpengaruh & 177 & 91,2 & 17 & 8,8 & $75(100)$ & & \\
\hline Tidak Terpenagruh & 59 & 37,8 & 97 & 62,2 & $275(100)$ & 0,049 & \\
\hline
\end{tabular}


Tabel 4

Pemodelan Multivariat Akhir

\begin{tabular}{llclcl}
\hline No & Variabel & \multicolumn{1}{c}{$\boldsymbol{P}$} & OR & \multicolumn{2}{c}{$(\mathbf{9 5 \%}$ CI) } \\
\cline { 5 - 6 } & & value & & Lower & Upper \\
\hline $\mathbf{1}$ & $\begin{array}{l}\text { Pengetahuan } \\
\text { tentang } \\
\text { kebijakan }\end{array}$ & $\mathbf{0 . 0 0 0}$ & $\mathbf{2 5 , 7 8 4}$ & $\mathbf{1 1 , 0 4 6}$ & $\mathbf{6 0 . 1 8 4}$ \\
& & & & \\
\hline KTR & $\begin{array}{l}\text { Lingkungan } \\
\text { pergaulan }\end{array}$ & $\mathbf{0 , 0 0 0}$ & $\mathbf{2 6 , 3 4 4}$ & $\mathbf{1 2 , 9 7 4}$ & $\mathbf{5 3 , 4 9 3}$ \\
\hline
\end{tabular}

\section{PEMBAHASAN}

\section{Pengetahuan kebijakan KTR yang Berhubungan dengan Implementasi Kebijakan KTR \\ Pengetahuan tentang kebijakan KTR} berhubungan secara signifikan dengan implementasi kebijakan KTR. Mahasiswa yang pengetahuan kebijakan KTR masih kurang lebih berpeluang 25 kali untuk tidak terlaksananya dengan pengetahuanyang tinggi tentang kebijakan KTR dimana diperoleh nilai $(95 \% \quad$ CI $)=15,594 \quad(11,046-60,184) \cdot$ Pengetahuan terhadap kebijakan KTR menyebabkan implementasi kebijakan KTR. Pengetahuan merupakan domain yang sangat penting untuk terbentuknya tindakan seseorang. Apabila perilaku didasari pengetahuan, kesadaran dan sikap positif maka perilaku tersebut akan bersifat langgeng (long tasting). Sebaliknya apabila perilaku itu tidak didasari oleh pengetahuan dan kesadaran maka tidak akan berlangsung lama,Notoatmodjo (2005).

Penelitian ini sesuaidengan penelitian Puswitasari (2012) yang menyatakan adanya hubungan antara pengetahuan peraturan kawasan tanpa rokok dengan tingkat kepatuhan. Namun dalam penelitian Imelda (2012) menyatakan tidak terdapat hubungan antara pengetahuan dengan tingkat pastisipasi penerapan KTR karena dalam mewujudkn KTR yang berhasil diperlukan kesadaran, kesediaan melakukan yang tumbuh dari dalam lubuk hati sendiri tanpa di paksa orang lain serta memiliki rasa tanggung jawab untuk mewujudkan partisipasi KTR. Hal ini sejalan dengan penelitian Amaliani (2012) yang menyatakan bahwa, tidak ada hubungan pengetahuan siswa yang baik, terhadap tindakan merokok pada siswa SMK Satria Nusantara.

\section{Lingkungan Pergaulan Berhubungan dengan Implementasi Kebijakan KTR}

Lingkungan pergaulan berhubungan secara signifikan dengan implementasi kebijakan KTR. mahasiswa yang tidak terpengaruh terhadaplingkungan pergaulanlebih berpeluang 26 kali untuk Tidak terlaksananya dengan lingkungan pergaulan yang benar dimana diperoleh nilai $(95 \% \mathrm{CI})=(12,974-$ 53,493). Lingkungan pergaulan menyebabkan implementasi kebijakan.Pendapat lain menyebutkan, perilaku merokok merupakan fungsi dari lingkungan dan individual. Dengan kata lain, perilaku merokok selain disebabkan dari faktor dalam diri sendiri, juga disebabkan oleh faktor lingkungan.

Penelitian ini sesuai dengan penelitian Puswitasari (2012) yang menyatakan adanya hubungan antara pengaruh lingkungan dengan tingkat kepatuhan. Hal ini juga sesuai dengan penelitian Imelda (2012) yang menyatakan adanya hubungan antara sikap tentang rokok dan kebijakan KTR dengan partisipasi penerapan kawasan tanpa rokok. Namun tidak sejalan dengan penelitian Hal ini tidak sejalan dengan penelitian yang dilakukan oleh Purba (2009) yang menyatakan bahwa tidak ada hubungan antara sikap responden tentang rokok dengan kebiasaan merokok siswa SMA Parulian 1 Medan.Sedangkan menurut Leventhal didapatkan data bahwa merokok pada tahap awal dilakukan dengan teman-temannya (64\%), seorang anggota keluarga namun bukan orang tua (23\%), namun terdapat pula yang sebagian besar juga dengan orang tua $(14 \%)$.Hal ini didukung dengan sebuah penelitian oleh Komalasari dan Helmi pada tahun 2000 yang mengatakan bahwa ada tiga faktor penyebab perilaku merokok pada remaja yaitu kepuasan psikologis, sikap permisif orang tua terhadap perilaku merokok remaja dan teman sebayanya.

Tabel 5

Hubungan Sebab Akibat Variabel Independen dengan Implementasi Kebijakan KTR di Lingkungan STIKes Hang Tuah Pekanbaru Tahun 2013

\begin{tabular}{lll}
\hline & \multicolumn{2}{l}{ Variabel independen } \\
\cline { 2 - 3 } Butir kriteria & $\begin{array}{l}\text { Lingkungan } \\
\text { pergaulan }\end{array}$ & $\begin{array}{l}\text { Pengetahuan } \\
\text { kebijakan } \\
\text { KTR }\end{array}$ \\
\hline Temporal & $+/-$ & $+/-$ \\
\hline Plausibility & + & + \\
\hline Konsistensi & + & + \\
\hline Kekuatan asosiasi & 26,344 & 25,784 \\
\hline $\begin{array}{l}\text { Dose response } \\
\text { relationship }\end{array}$ & - & - \\
\hline Jenis disain & - & - \\
\hline
\end{tabular}

\section{IMPLIKASI HASIL SEBAB AKIBAT}

\section{Pengetahuan Kebijakan KTR dengan Implementasi Kebijakan KTR}

Hasil penelitian menunjukkan terdapat hubungan yang bermakna antara pengetahuan kebijakan KTR dengan implementasi kebijakan kawasan tanpa rokok di STIKes Hang Tuah Pekanbaru. Berdasarkan hasil penelitian ada kecenderungan antara yang memiliki pengetahuan 
tidak baikterhadap kebijakan KTR di bandingkan dengan yang baik terhadap kebijakan tersebut. Oleh karena itu, Alternatif pemecahan masalahnya adalah kebijakan kampus larangan merokok hendaknya benarbenar diterapkan dan sebaiknya selalu di lakukan monitoring atau pengawasan dan membuat sanksisanksi yang lebih tegas lagi oleh pihak pengambil keputusan agar kebijakan kampus KTR tersebut dapat berjalan sesuai dengan yang diharapkan.

\section{Lingkungan Pergaulan dengan Implementasi Kebijakan KTR}

Hasil penelitian menunjukkan terdapat hubungan yang bermakna antara lingkungan pergaulan dengan implementasi kebijakan kawasan tanpa rokok di STIKes Hang Tuah Pekanbaru. Berdasarkan hasil penelitian ada kecenderungan antara mahasiswa yang terpengaruh oleh lingkungan pergaulan di bandingkan dengan yang tidak terpengaruh oleh lingkungan pergaulan. Oleh Karena itu, Alternatif pemecahan masalahnya adalah dengan menegur langsung dan memberikan peringatan bagi mahasiswa yang ketahuan merokok di lingkungan kampus karena kerugian akibat asap rokok bukan hanya terkena pada perokok aktif tetapi perokok pasif juga bisa terkena imbas dari asap rokok. Oleh karena itu lingkungan pergaulan yang ada di sekitar kampus juga merupakan peranan yang sangat penting untuk di pantau.

\section{Variabel Independen yang Tidak Berhubungan dengan Implementasi Kebijakan KTR}

\section{Pengetahuan Bahaya Merokok}

Sebagian mahasiswa memiliki pengetahuan yang baik tentang bahaya merokok.Pada penelitian ini sesuai dengan hasil analisis multivariat bahwa variabel pengetahuan tentang bahaya merokok tidak berhubungan dengan implementasi kebijakan KTR.Menurut peneliti hal tersebut disebabkan karena mahasiswa yang sudah tahu tentang bahaya merokok belum memiliki kesadaran untuk merubah perilaku menjadi lebih baik lagi agar tidak merokok. Selain itu juga karena pengaruh teman di lingkungan yang banyak merokok, kebijakan tentang merokok dilingkungan kampus belum berjalan optimal, dan bahaya yang ditimbulkan akibat merokok belum langsung dirasakan oleh mahasiswa karena sebagian besar bahaya merokok merupakan efek jangka panjang yang akan dirasakan.

\section{KESIMPULAN}

Proporsi mahasiswa STIKes HTP tahun 2013 yang tidak mematuhi kebijakan KTR sebesar $67,4 \%$. Pengetahuan tentang kebijakan KTR berhubungan dengan implementasi kebijakan KTR artinya mahasiswa dengan pengetahuan tidak baik tentang kebijakan KTR.Lingkungan pergaulan berhubungan implementasi kebijakan KTR artinya mahasiswa yang terpengaruh oleh lingkungan pergaulan.Variabel independen yang tidak memiliki hubungan secara statistik signifikan dengan implementasi kebijakan KTR adalah pengetahuan bahaya merokok.Dalam penelitian ini tidak terdapat counfounding.

\section{SARAN}

Melakukan sosialisasi kepada mahasiswa STIKes HTP tentang kebijakan KTR khususnya di Lingkungan STIKes HTP agar pengetahuan mahasiswa lebih baik dan mahasiswa bisa menerapkan kebijakan KTR tersebutdan memberikan sanksi-sanksi yang tegas kepada seluruh civitas akademika STIKes HTP yang melanggar peraturan KTR.

\section{UCAPAN TERIMA KASIH}

Ucapan terima kasih ditujukan kepada Bapak dr. ZainalAbidin, MPH, selaku Ketua Sekolah TinggiI lmu Kesehatan (STIKes) Hang Tuah Pekanbaru. Bapak Prof. DR. Buchari Lapau, dr, MPH selaku Ketua Sidang, Bapak Sumengen Sutomo, SKM, MPH, DrPH sebagai Pembimbing 1 yang telah banyak memberikan dukungan dan arahan, bimbingan, masukan koreksi dalam penulisan ini.

\section{DAFTAR PUSTAKA}

Amaliani,T.2012.Gambaran Karakteristik dan Sosial Budaya keluarga dalam Hal Perilaku merokok siswa SMK Satria Nusantara Binjai.Skripsi FKM-USU.Medan. Di akses 21 Juni 2013.

Badan Penelitian dan Pengembangan Kesehatan, (2010), Riset Kesehatan Dasar (Riskesdas 2010), Kementerian Kesehatan Republik Indonesia, Jakarta.

Chistina, I, 2012. Pengaruh Pengetahuan Dan Sikap Guru Dan Siswa Tentang Rokok Dan Kebijakan Kawasan Tanpa Rokok TerhadapPartisipasi Dalam Penerapan Kawasan Tanpa Rokok Di Smp Negeri 1 Kota Medan Tahun 2012. Di akses 21 Juni 2013.

Kemenkes, RI, 2010. Pedoman Teknis Kawasan Tanpa Rokok ; Jakarta.

Lapau, 2010. Metodelogi Penelitian Kesehatan. Yayasan Pustaka Obor Indonesia, Jakarta.

Notoatdmojo, 2005. Metodologi Penelitian Kesehatan, Jakarta: Rineka Cinere

Peraturan Bersama Menteri Kesehatan dan Menteri Dalam Negeri No. 188/MENKES/PB/I/2011 No.7 Tahun 2011.

PP No.75 Tahun 2005. Kawasan Larangan Merokok. Online (http://www.fas.usda.gov) di akses 27 Februari 2013. 
Purba,YC.2009.Hubungan Pengetahuan dan Sikap Remaja Laki-laki Terhadap Kebiasaan Merokok di SMU Parulian 1 Medan.Skripsi FKM-USU Medan.

Puswita Sari, A. 2012.faktor kepatuhan mahasiswa dan karyawan terhadap peraturan kawasan tanpa rokok di lingkungan kampus fakultas kedokteran universitas diponegoro. Jurnal Media Medika Utama, Online di akses 8 Mei 2013.
Sutris, 2011. Proses Kebijakan Kawasan Dilarang Merokok. Online (http://www.google.com) di akses 27 februari 2013.

Undang-Undang Republik Indonesia No.36 Tahun 2009 Pasal 115 Tentang Kawasan Tanpa Rokok.

Yudhia, M dan Sri Hidajati, R. Analisis Perilaku Konsumen Rokok Di Kalangan Mahasiswa. Jurnal Ilmiah Magister Manajemen. Online di akses 5 Mei 2012. 